\title{
Genetic characteristics and polymorphisms in the chicken interferon-induced transmembrane protein (IFITM3) gene
}

\author{
Yong-Chan Kim ${ }^{1,2} \cdot$ Min-Ju Jeong ${ }^{1,2} \cdot$ Byung-Hoon Jeong ${ }^{1,2}$ (B)
}

Received: 15 March 2019 / Accepted: 5 August 2019 / Published online: 13 August 2019

(C) Springer Nature B.V. 2019

\begin{abstract}
The interferon-induced transmembrane protein 3 (IFITM3) gene is classified as a small interferon-stimulated gene and is associated with a broad spectrum of antiviral functions against several fatal enveloped viruses, including influenza A viruses (IAVs). The rs12252 single nucleotide polymorphism (SNP) of the IFITM3 gene in humans was associated with susceptibility to H1N1 influenza in a 2009 pandemic. In addition, overexpression of the IFITM3 protein potently inhibits the highly pathogenic avian influenza H5N1 virus in ducks and chickens. Although chickens are a major host of influenza viruses and the IFITM3 gene participates in the host antiviral system, studies on chicken IFITM3 gene are very rare. To investigate the genetic characteristics of the chicken IFITM3 gene, we performed direct sequencing and alignment in 108 Dekalb White and 72 Ross breeds. We also investigated the genotype and haplotype frequencies and linkage disequilibrium of the IFITM3 gene polymorphisms and evaluated whether the non-synonymous SNPs are deleterious. We found significantly different genotype, allele and haplotypes frequencies between two chicken breeds, Dekalb White and Ross. Furthermore, we compared and analyzed the promoter structure of the chicken IFITM3 gene with that of several species. We found that birds have a long C-terminal domain and inverted topology of the IFITM3 protein compared to mammals. We also identified fourteen genetic polymorphisms in the chicken IFITM3 gene. L100 M and N125H were predicted as 'probably damaging' and L100 M can alter the length of its conserved intracellular loop (CIL). Furthermore, chickens, but not mammals, contain CpG islands (CGIs) in this promoter region.
\end{abstract}

Keywords Chickens $\cdot$ Interferon-stimulated gene $\cdot$ IFITM3 $\cdot$ Promoter $\cdot$ SNP $\cdot$ Topology

\section{Introduction}

The interferon-induced transmembrane protein 3 (IFITM3) gene is an endogenous immune-related gene classified as a small interferon-stimulated gene (ISG) (Friedman et al. 1984). The IFITM3 protein prevents viral infection by restricting viral membrane hemifusion between the host and viral membrane and exhibits a broad spectrum of potent antiviral capacity against enveloped viruses, including influenza A viruses (IAVs), Ebola virus (EBOV), Marburg virus (MARV), severe acute respiratory syndrome coronavirus (SARS-CoV), dengue virus (DEV), West Nile virus (WNV)

\section{Byung-Hoon Jeong}

bhjeong@jbnu.ac.kr

1 Korea Zoonosis Research Institute, Chonbuk National University, 820-120, Hana-ro, Iksan, Jeonbuk 54531, Republic of Korea

2 Department of Bioactive Material Sciences, Chonbuk National University, Jeonju, Jeonbuk 54531, Republic of Korea and Zika virus (ZIKV) (Diamond and Farzan 2013; Li et al. 2013; Santhakumar et al. 2017; Savidis et al. 2016).

The IFITM3 protein is localized in the late endosome to prevent viral invasion (Feeley et al. 2011). For this reason, the IFITM3 protein has a conserved sorting signal that is needed to enter the endosomal pathway. This signal peptide domain, referred to as $\mathrm{Yxx} \phi$, a tyrosine-based lysosomal targeting motif, is located in the N-terminal domain (NTD) of the IFITM3 protein (Jia et al. 2014). This signal peptide is conserved in species including mammals and birds and is used as classification criteria between IFITM1 and IFITM3 proteins, because these two proteins share a highly similar protein sequence (Wang et al. 2017). Mutagenesis of the Yxxф domain augmented mislocalization of the IFITM3 protein and reduced its antiviral capacity in mammals (Jia et al. 2012). However, in a recent study performed in ducks, the Yxx $\phi$ domain was not essential for correct localization of the IFITM3 protein and did not affect antiviral capacity (Blyth et al. 2015). Although mammals and birds share a very similar protein structure called CD225, which is significantly associated with antiviral 
ability, birds do not likely depend on the $\mathrm{Yxx} \phi$ domain for correct IFITM3 protein localization. Thus, structural analysis of the IFITM3 protein between mammals and birds is highly desirable to identify genetic differences that can reveal other crucial differences between these two classes.

Previous studies have shown that single nucleotide polymorphisms (SNPs) in the human IFITM3 gene are associated with antiviral ability. The rs12252 SNP, which is located in a splicing acceptor site, results in an $\mathrm{N}$-terminal truncated form of human IFITM3 protein, and has been related to the severity of H1N1 influenza infection in a 2009 pandemic. Two studies in British and Han Chinese populations reported that the rs12252 SNP is related to disease severity, and one metaanalysis reaffirmed that individuals with the CC genotype have a high risk of influenza infection (Everitt et al. 2012; Kim and Jeong 2017b; Xuan et al. 2015; Zhang et al. 2013). Furthermore, susceptibility to ulcerative colitis (UC) and hemorrhagic fever with renal syndrome is associated with polymorphisms in the IFITM3 gene (Seo et al. 2010; Xu-Yang et al. 2016). Although genetic polymorphisms in the IFITM3 gene play a crucial role in immunity against viral diseases in humans and mice, polymorphisms in this gene have not yet been investigated in chickens.

The purpose of this study was to investigate the genetic characteristics of the chicken IFITM3 gene by comparison among several species. We performed sequence alignment using ClustalW2 and predicted transmembrane domains of the IFITM3 protein using TMpred and SOSUI in humans, monkey, mice, rat, ducks, geese and chickens. We also investigated the genotype, allele, and haplotype frequencies and linkage disequilibrium (LD) among the polymorphisms in the IFITM3 gene in chickens and predicted whether the non-synonymous SNPs are benign or damaging using PolyPhen-2 and the impact of non-synonymous SNPs according to transmembrane topology. Furthermore, we investigated $300 \mathrm{bp}$ upstream from the transcription start site (TSS) of the chicken IFITM3 gene to compare and analyze the promoter structure of the chicken IFITM3 gene with that of several species.

\section{Materials and methods}

\section{Ethical statement}

Dekalb White and Ross (3 weeks old) breeds were obtained from slaughter house in South Korea. All experimental procedures and animal care performed in the present study were approved according to the recommendations of the Guide of the Animal Care and Use Committee of Chonbuk National University (IACUC Number: CBNU 2017-0030) and all efforts were made to minimize suffering.

\section{Genetic analysis of the IFITM3 gene}

Genomic DNA was isolated from $20 \mathrm{mg}$ muscle tissue using the LaboPass Tissue Genomic DNA Isolation Kit (Cosmo Genetech CO., Ltd., Korea) following the manufacturer's instructions. Polymerase chain reaction (PCR) was performed with forward and reverse primers as follows: chicken IFITM3-1F (CACTTGACGGGGACACAGTT) and chicken IFITM3-1R (CTCTCCCGACGCCATCATTT), chicken IFITM3-2F (CATGCATCCCACAGAGCTCC) and chicken IFITM3-2R (ATCCCTGTCACGCTCCAGAA). The PCR reagents contained $25 \mathrm{pmol}$ of each primer, $5 \mu \mathrm{l}$ of $10 \times \mathrm{Taq}$ DNA polymerase buffer, $1 \mu \mathrm{l}$ of $10 \mathrm{mM}$ dNTPs and 2.5 units of Taq DNA polymerase (Promega, USA). The PCR conditions were as follows: $94^{\circ} \mathrm{C}$ for $2 \mathrm{~min}$ to denature, and $35 \mathrm{cy}$ cles of $94{ }^{\circ} \mathrm{C}$ for $45 \mathrm{~s}, 63^{\circ} \mathrm{C}$ for $45 \mathrm{~s}$, and $72{ }^{\circ} \mathrm{C}$ for $1 \min 30 \mathrm{~s}$, and then 1 cycle of $72{ }^{\circ} \mathrm{C}$ for $10 \mathrm{~min}$ to extend the reaction. The S-1000 Thermal Cycler (Bio-Rad Laboratories, USA) was used. A $5 \mu \mathrm{l}$ aliquot of the PCR product was analyzed by electrophoresis on a $1 \%$ agarose gel stained with ethidium bromide (EtBr) to determine the target band size (IFITM3-1, $710 \mathrm{bp}$; IFITM3-2, $630 \mathrm{bp}$ ). The purification of PCR products for DNA sequencing was performed using a QIAquick Gel Extraction Kit (Qiagen, USA). The PCR products were directly sequenced on an ABI 3730 automatic sequencer using a Taq Dideoxy Terminator Cycle Sequencing Kit (ABI, USA).

\section{Statistical analysis}

Genotype and allele frequencies of chicken IFITM3 gene were compared between Dekalb White and Ross breeds by chisquare test using SAS 9.4 Software (SAS Institute Inc., Cary, NC, USA). Haplotype and LD among fourteen polymorphisms were analyzed by the Haploview version 4.2 (Broad Institute, Cambridge, MA, USA).

\section{Prediction of IFITM3 protein functional alterations}

Possible impacts on the IFITM3 protein caused by nonsynonymous SNPs were predicted by PolyPhen-2 (http:// genetics.bwh.harvard.edu/pph2/index.shtml). The PolyPhen2 score corresponds to the probability of a substitution being damaging and ranges from 0.0 to 1.0. The prediction outcome can be presented as 'benign', 'possibly damaging' or 'probably damaging'. The prediction algorithm is based on phylogenetic, structural, and sequence information.

\section{Sequence comparison and transmembrane domain prediction of the IFITM3 protein}

Protein sequence alignment was performed using ClustalW2 (http://www.ebi.ac.uk/Tools/msa/clustalo). The transmembrane domains in the IFITM3 protein were 
predicted by TMpred (http://www.ch.embnet.org/software/ TMPRED form.html) and SOSUI (http://harrier.nagahamai-bio.ac.jp/sosui/sosui_submit.html). Protein sequences of IFITM3 protein were obtained from GenBank at National Center for Biotechnology Information (NCBI), including those of human (Homo sapiens, AFF60355.1), monkey (Cercopithecus albogularis, ANJ01447.1), mouse (Mus musculus, NP_079654.1), rat (Rattus norvegicus, NP 001129596.1), duck (Anas platyrhynchos, AQX83312.1), goose (Anser cygnoides, AQM74179) and chicken (Gallus gallus, in this study).

\section{Promoter comparison of the IFITM3 gene}

DNA sequences of the promoter and open reading frame (ORF) of the IFITM3 gene were obtained from GenBank at NCBI, including those of human (Homo sapiens, NC_000011.10), mouse (Mus musculus, NC_000073.6) and chicken (Gallus gallus, in this study). Among the promoter sequences, TATA box and CpG islands (CGIs), which are important promoter elements, were investigated. The promoter elements were searched for using GPMiner (http://gpminer. mbc.nctu.edu.tw/index.php), which is based on the Naive Bayes model.

\section{Results}

\section{Sequence comparison and transmembrane prediction of the IFITM3 protein}

DNA sequences of the IFITM3 gene ORF sequenced in 108 Dekalb White and 72 Ross were identical to those of the Gallus gallus gene registered in GenBank (NP_001336990.1). Multiple sequence alignment showed very low homology in the NTD and C-terminal domain (CTD) between mammals and birds (Fig. 1). Since the amino acid sequence of the IFITM3 protein determines the transmembrane structure, we predicted transmembrane domains using TMpred and SOSUI (Fig. 2, Table 1). Notably, the length of the NTD in mammals is 11 or 12 amino acids longer than that in birds. However, the length of the CTD (4 amino acids in humans and monkey, and 7 amino acids in mice and rat) is shorter than that in birds. The 16 amino acid length of the CTD in chickens is shorter than that in ducks and geese, and the lengths of other domains in chickens are very similar. In addition, prediction by TMpred indicated that IFITM3 protein in birds prefers the outside-to-inside topology of transmembrane domain 1 (TM1) and the inside-tooutside topology of transmembrane domain 2 (TM2). This topology prediction is the opposite of that of mammals (i.e., humans, monkey, mice and rat prefer the inside-to-outside topology of TM1 and the outside-to-inside topology of TM2).

\section{Identification of polymorphisms in the chicken IFITM3 gene and analysis of haplotype frequencies and LD}

To investigate the genotype and allele frequencies of IFITM3 gene polymorphisms in chickens, we screened polymorphisms within two exons of the chicken IFITM3 gene through automatic direct sequencing in 108 Dekalb White and 72 Ross breeds. We found a total of thirteen SNPs and one insertion/ deletion, including three non-synonymous SNPs, c.298C > A $(\mathrm{L} 100 \mathrm{M})$, c. $307 \mathrm{G}>\mathrm{A}(\mathrm{V} 103 \mathrm{I})$ and c.373A $>\mathrm{C}(\mathrm{N} 125 \mathrm{H})$ (Fig. 3). Interestingly, genotype of nine polymorphisms, including c. $-338 \mathrm{G}>\mathrm{A}$, c. $-330 \mathrm{G}>\mathrm{C}$, c. $-295 \mathrm{G}>\mathrm{T}$, c. $213+$ $18 \mathrm{G}>\mathrm{T}$, c. $214-5 \mathrm{C}>\mathrm{T}$, c. $307 \mathrm{G}>\mathrm{A}$, c. $373 \mathrm{~A}>\mathrm{C}$, c. $657+$ $29 \mathrm{~T}>\mathrm{G}$ and c.657 + 47_657+48InsAG showed statistically different distribution between Dekalb White and Ross breeds. In addition, ten polymorphisms, including c.-330G $>$ C, c.$295 \mathrm{G}>\mathrm{T}$, c. $213+18 \mathrm{G}>\mathrm{T}$, c. $214-5 \mathrm{C}>\mathrm{T}$, c. $307 \mathrm{G}>\mathrm{A}$, c. $373 \mathrm{~A}>\mathrm{C}$, c. $493 \mathrm{~A}>\mathrm{C}$, c. $657+29 \mathrm{~T}>\mathrm{G}$, c. $657+$ 47 657+48InsAG and c.657+64 $\mathrm{T}>\mathrm{C}$ have significantly different allele distribution between Dekalb White and Ross breeds (Table 2).

To determine whether there was strong $L D$ among the fourteen polymorphisms in the chicken IFITM3 gene, the $\left(\left|\mathrm{D}^{\prime}\right|\right)$ was calculated. Detailed LD values with $\left|\mathrm{D}^{\prime}\right|$ scores were described in Table 3. To analyze the haplotype frequencies, we investigated the distribution of haplotypes using Haploview version 4.2. Seven major haplotypes of chicken IFITM3 gene were found in Dekalb White breeds (Table 4). Among the seven haplotypes, the GGGTCCGAGATWtCT haplotype was the most frequently observed (39.6\%). Interestingly, the Ross breed had a significantly different haplotype distribution within the chicken (Table 5). A total of nine haplotypes were identified in the the Ross breed and most frequently observed haplotype was the ACGGTCAAGAGWtCT haplotype. The most frequent haplotypes were different between the two chicken breeds.

\section{Predicting the impact of polymorphisms in the chicken IFITM3 gene}

In a previous study in humans, the rs 12252 polymorphism in the IFITM3 gene was determined to impact protein structure and trigger a deleterious effect on the severity of IAV-infected patients during a 2009 pandemic. To evaluate the degree of damage of three non-synonymous SNPs, L100 M, V103I and $\mathrm{N} 125 \mathrm{H}$, we used PolyPhen-2 and SOSUI program. L100 M and $\mathrm{N} 125 \mathrm{H}$ were predicted to be 'probably damaging' with scores of 0.993 and 0.969 , respectively (data not shown). It is also important to note that L100 M, V103I and N125H are located in the TM2 region according to the SOSUI program; therefore, we assumed that these three non-synonymous SNPs will affect transmembrane structure. Thus, we divided these three non-synonymous SNPs into eight haplotypes (100 L/ 
Human (AFF60355.1) MNHTVQTFFSPVNSGQPPNYEMLKEEHEVAVLGAPHNPAPPTSTVIHIRSETSVPDHVVW Monkey (ANJ01447.1) MNHTVQTEFSPVNSGQPPNYEILKEEHEVAVLGAPHNPAPPTSTVIHIRSETSVPDHVVW Mouse (NP 079654.1) MNHTSQAFITAASGGQPPNYERIKEEYEVAEMGAPHGSASVRTTVINMPREVSVPDHVVW Rat (NP_001129596.1) MNHTSQAFVNAATGGQPPNYERIKEEYEVSELGAPHGSASVRTTVINMPREVSVPDHVVW Duck (AQX83312.1) ME------RTRAPGLALPPYEPLVEGMDMENM-----SRSVVVPVEPPPVQAPPRDHLAW Goose (AQM74179) ME-----RTRAPGVSLPPYEPLVEGLDMENM-----SRSVVVPVEAPPVQPPPRDHLAW Chicken (In this study) ME------RVRASGPGVPPYEPLMDGMDMEGK-----TRSTVVTVETP-LVPPPRDHLAW

Human (AFF60355.1) SLFNTLFMNPCCLGFIAFAYSVKSRDRKMVGDVTGAQAYASTAKCLNIWALILGILMTIL

Monkey (ANJ01447.1) SLFNTLFMNPCCLGFIAFAYSVKSRDRKMVGDLTGAQAYASTAKCLNIWALILCIFMTIL

Mouse (NP_079654.1) SLFNTLFMNFCCLGFIAYAYSVKSRDRKMVGDVTGAQAYASTAKCLNISTLVLSILMVVI

Rat (NP_001129596.1) SLFNTLFMNFCCLGFIAYAYSVKSRDRKMVGDMTGAQAYASTAKCLNISSLVLSILMVII

Duck (AQX83312.1) SLCSTLYSNVCCLGFLALVFSVKSRDRKVLGDYSGALSYGSTAKYLNITALLLNIFEIIL

Goose (AQM74179) SLCSTLYANVCCLGFLALVFSVKSRDRKVLGDYSGALSYGSTAKYLNITALLLNIFLVIL

Human (AFF60355.1) LIVIPVL---IFQAYG---

Monkey (ANJ01447.1) LIVIPVL---ILQAYQ--------------- 133

$\begin{array}{lll}\text { Mouse (NP_079654.1) } & \text { TIVSVII---IVLNAQNLHT-- }---------- & 137\end{array}$

$\begin{array}{lll}\text { Rat (NP_001129596.1) TIVTVVI---IALNAPRLQT------------ } & 137\end{array}$

Duck (AQX83312.1) IIALIASGTITFVNLLNQQQQQQGNHPFYGPT 141

Goose (AQM74179) IVALIASGTITIVNLLNHQQQQQGNHPELGPT 141

Chicken (In this study) IIALVASGTIMVANIFNHQQQH---PEFIGPT 137

Fig. 1 Comparison of IFITM3 amino acid sequences in humans, mice, ducks, geese and chickens. IFITM3 protein sequences were obtained from GenBank at the National Center for Biotechnology Information (NCBI), including those of human (Homo sapiens, AFF60355.1), monkey (Cercopithecus albogularis, ANJ01447.1), mouse (Mus musculus, NP_079654.1), rat (Rattus norvegicus, NP

$103 \mathrm{~V} / 125 \mathrm{~N}, 100 \mathrm{~L} / 103 \mathrm{~V} / 125 \mathrm{H}, 100 \mathrm{~L} / 103 \mathrm{I} / 125 \mathrm{~N}, 100 \mathrm{~L} /$ $103 \mathrm{I} / 125 \mathrm{H}, 100 \mathrm{M} / 103 \mathrm{~V} / 125 \mathrm{~N}, 100 \mathrm{M} / 103 \mathrm{~V} / 125 \mathrm{H}, 100 \mathrm{M} /$
001129596.1), duck (Anas platyrhynchos, AQX83312.1), goose (Anser cygnoides, AQM74179) and chicken, (Gallus gallus, in this study). Protein sequences were aligned using ClustalW2. Colors indicate the chemical properties of amino acids; blue: acidic, red: small and hydrophobic, magenta: basic, green: hydroxyl, sulfhydryl, amine and glycine

$103 \mathrm{I} / 125 \mathrm{~N}$ and $100 \mathrm{M} / 103 \mathrm{I} / 125 \mathrm{H})$ and performed transmembrane prediction by SOSUI (Table 6). Interestingly, the $100 \mathrm{M}$

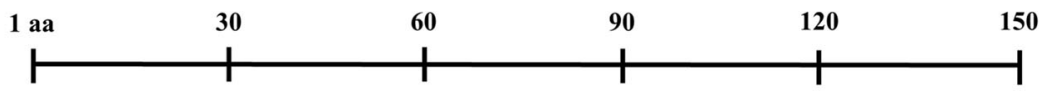

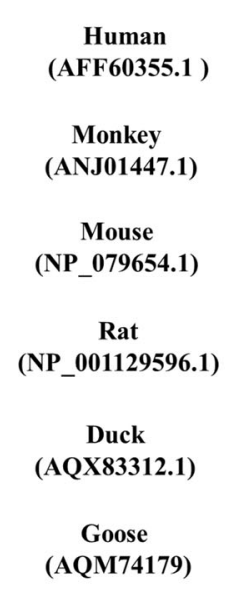

L
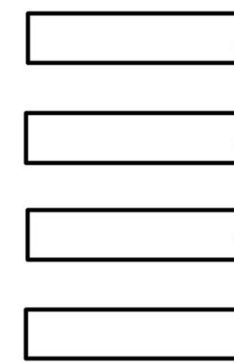

61

\section{9}

61

19

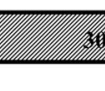

तो
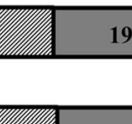

6

19

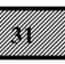

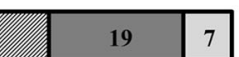

61

19

บบบากา

V)

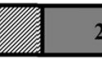

20

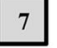

137 aa

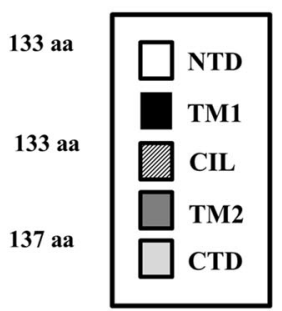

141 aa

141 aa

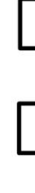

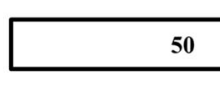

Chicken
(In this study)

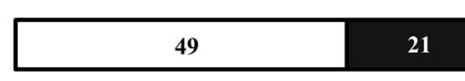

21
Fig. 2 Comparison of IFITM3 protein structure in humans, mice, ducks, geese and chickens. Transmembrane topology was predicted by SOSUI. IFITM3 protein sequences were obtained from GenBank at NCBI, including those of human (Homo sapiens, AFF60355.1), monkey (Cercopithecus albogularis, ANJ01447.1), mouse (Mus musculus, NP_079654.1), rat (Rattus norvegicus, NP_001129596.1), duck (Anas platyrhynchos, AQX83312.1), goose (Anser cygnoides, AQM74179) and chicken, (Gallus gallus, in this study). Numbers in boxes indicate the number of amino acids of each domain. Abbreviations in boxes are as follows: NTD (N-terminal domain), TM1 (transmembrane domain 1), CIL (conserved intracellular loop), TM2 (transmembrane domain 2), and CTD (C-terminal domain) 
Table 1 Transmembrane domains of IFITM3 protein predicted by TMpred and SOSUI

\begin{tabular}{|c|c|c|c|c|c|}
\hline Prediction methods & Species & Transmembrane domain & Position & Length & $\mathrm{TM}^{*}$ \\
\hline \multirow[t]{14}{*}{ TMpred } & \multirow[t]{2}{*}{ Human } & LFNTLFMNPCCLGFIAFAY & $62-80(\mathrm{i} \rightarrow \mathrm{o})^{* *}$ & 19 & TM1 \\
\hline & & LILGILMTILLIVIPVLIF & $111-129(\mathrm{o} \rightarrow \mathrm{i})^{* * *}$ & 19 & TM2 \\
\hline & \multirow[t]{2}{*}{ Monkey } & LFNTLFMNPCCLGFIAFAY & $62-80(\mathrm{i} \rightarrow \mathrm{o})$ & 19 & TM1 \\
\hline & & LILCIFMTILLIVIPVLIL & $111-129(\mathrm{o} \rightarrow \mathrm{i})$ & 19 & TM2 \\
\hline & \multirow[t]{2}{*}{ Mouse } & LFNTLFMNFCCLGFIAYAY & $62-80(\mathrm{i} \rightarrow \mathrm{o})$ & 19 & TM1 \\
\hline & & VLSILMVVITIVSVIIIVL & $112-130(\mathrm{o} \rightarrow \mathrm{i})$ & 19 & TM2 \\
\hline & \multirow[t]{2}{*}{ Rat } & LFNTLFMNFCCLGFIAYAY & $62-80(\mathrm{i} \rightarrow \mathrm{o})$ & 19 & TM1 \\
\hline & & LVLSILMVIITIVTVVIIAL & $111-130(\mathrm{o} \rightarrow \mathrm{i})$ & 20 & TM2 \\
\hline & \multirow[t]{2}{*}{ Duck } & LCSTLYSNVCCLGFLALVFSV & $51-71(0 \rightarrow i)$ & 21 & TM1 \\
\hline & & IFFIILIIALIASGTITFV & $104-122(\mathrm{i} \rightarrow 0)$ & 19 & TM2 \\
\hline & \multirow[t]{2}{*}{ Goose } & LCSTLYANVCCLGFLALVFSV & $51-71(0 \rightarrow i)$ & 21 & TM1 \\
\hline & & IFLVILIVALIASGTITIV & $104-122(\mathrm{i} \rightarrow 0)$ & 19 & TM2 \\
\hline & \multirow[t]{2}{*}{ Chicken } & LCTTLYANVCCLGFLALVFSV & $50-70(0 \rightarrow i)$ & 21 & TM1 \\
\hline & & VFLIILIIALVASGTIMVA & $103-121(\mathrm{i} \rightarrow 0)$ & 19 & TM2 \\
\hline \multirow[t]{14}{*}{ SOSUI } & \multirow[t]{2}{*}{ Human } & WSLFNTLFMNPCCLGFIAFAYS & $60-81$ & 22 & TM1 \\
\hline & & NIWALILGILMTILLIVIPVLIF & $107-129$ & 23 & TM2 \\
\hline & \multirow[t]{2}{*}{ Monkey } & WSLFNTLFMNPCCLGFIAFAYS & $60-81$ & 22 & TM1 \\
\hline & & NIWALILCIFMTILLIVIPVLIL & $107-129$ & 23 & TM2 \\
\hline & \multirow[t]{2}{*}{ Mouse } & WSLFNTLFMNFCCLGFIAYAYS & $60-81$ & 22 & TM1 \\
\hline & & TLVLSILMVVITIVSVIIIVLNA & $110-132$ & 23 & TM2 \\
\hline & \multirow[t]{2}{*}{ Rat } & WSLFNTLFMNFCCLGFIAYAYS & $60-81$ & 22 & TM1 \\
\hline & & SLVLSILMVIITIVTVVIIALNA & $110-132$ & 23 & TM2 \\
\hline & \multirow[t]{2}{*}{ Duck } & WSLCSTLYSNVCCLGFLALVFS & $49-70$ & 22 & TM1 \\
\hline & & ALLLNIFFIILIIALIASGTITF & $99-121$ & 23 & TM2 \\
\hline & \multirow[t]{2}{*}{ Goose } & WSLCSTLYANVCCLGFLALVFS & $49-70$ & 22 & TM1 \\
\hline & & ALLLNIFLVILIVALIASGTITI & $99-121$ & 23 & TM2 \\
\hline & \multirow[t]{2}{*}{ Chicken } & WSLCTTLYANVCCLGFLALVFS & $48-69$ & 22 & TM1 \\
\hline & & HLINVFLIILIIALVASGTIMVA & $99-121$ & 23 & TM2 \\
\hline
\end{tabular}

*TM indicates transmembrane domain

$* *(\mathrm{i} \rightarrow \mathrm{o})$ indicates inside-to-outside helices

$* * *(\mathrm{o} \rightarrow \mathrm{i})$ indicates outside-to-inside helices

allele changed its position in TM2 from 99 to 121 to 101-123 and the length of its conserved intracellular loop domain (CIL) from 29 to 31(data not shown).

\section{Comparison of promoter structure}

Previous studies have reported that the immune system and immune regulatory mechanisms differ significantly between mammals and birds. The promoter is the one of the major regulatory factors of protein expression. Thus, we postulated that the promoter structure may differ between mammals and birds. We analyzed $300 \mathrm{bp}$ upstream of the positive strand of the IFITM3 gene in humans, mice and chickens (Fig. 4). Notably, mammals do not contain a CGI in the proximal promoter. Remarkably, since the CGI in chickens has been distributed to the proximal promoter region and gene body of the
IFITM3 gene, the promoter structure in chickens differs significantly from that of mammals.

\section{Discussion}

The IFITM3 protein is a transmembrane protein and acts as the first line of host defense against a wide range of viruses (Brass et al. 2009; Schoggins et al. 2011; Weidner et al. 2010). The IFITM3 protein has a well-conserved structure: CD225, which consists of two major domains, TM1 and CIL. Previous studies have focused on conserved amino acid residues within two domains, including F75, F78, R87 and Y99. F75 and F78 within TM1 participate in the physical association between IFITM proteins, whereas R87 and Y99 within the CIL play a major role in the inhibition of orthomyxovirus. These 


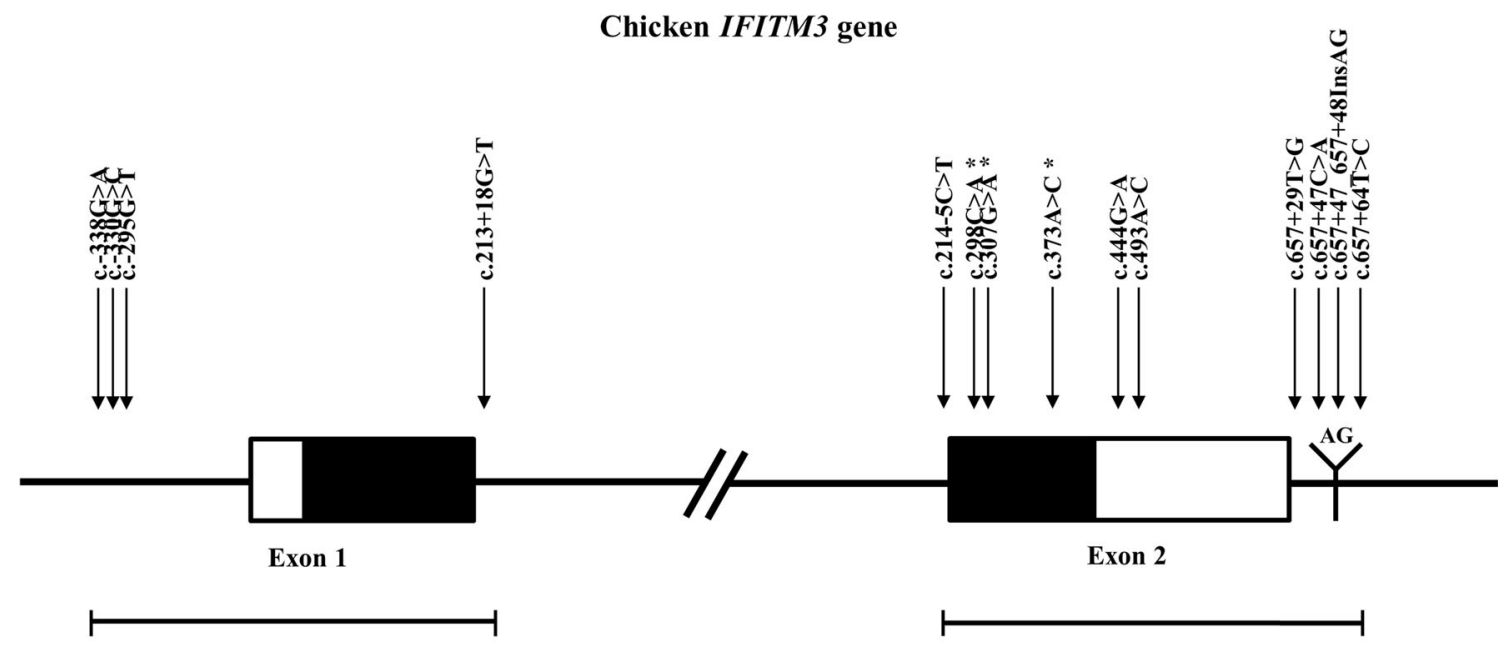

$1 \mathbf{k b}$

Fig. 3 Gene map and polymorphisms identified in the chicken interferon-induced transmembrane protein 3 (IFITM3) gene on chromosome 5. The open reading frame (ORF) within the exons is indicated by shaded blocks, and the $5^{\prime}$ and $3^{\prime}$ untranslated regions (UTRs) are indicated by white blocks. Edged horizontal bars indicate the regions

residues are well-conserved among several species and the substitution of these residues reduces the antiviral capacity of the IFITM3 protein (John et al. 2013). Another important domain of the IFITM3 protein is the NTD. NTD exhibits very low homology among species. However, its sorting signal motif, Yxx $\phi$ within the NTD, is well-conserved. Previous studies in human cell lines have reported that 20-YEML-23 is necessary for trafficking IFITM3 protein from the cell surface to the endosomal pathway. IFITM3 mutants targeting Y20 and L23 caused the IFITM3 protein to relocalize to the cell periphery (Jia et al. 2012; Jia et al. 2014). However, in a recent study in ducks, IFITM3 mutants targeting the Yxxф motif were correctly localized in the LAMP-1-expressing late endosome. Because the canonical sorting signal motif of duck IFITM3 protein does not participate in correct localization, we performed sequence alignment among humans, mice and several bird species to identify differences in the IFITM3 protein between mammals and birds. The NTD and CTD of the IFITM3 protein showed very low homology between mammals and birds (Fig. 1). Differences in the amino acid sequence can change the topology of the transmembrane structure. Thus, we performed transmembrane prediction using TMpred and SOSUI to compare the structure of IFITM3 proteins (Table 1, Fig. 2). Interestingly, the prediction revealed three differences in the IFITM3 protein between mammals and birds. However, this prediction was carried out on limited sequenced. Arrows indicate the polymorphisms found in this study. Asterisks denote non-synonymous single nucleotide polymorphisms (SNPs). The Y-shaped bar indicates the insertion/deletion identified in the IFITM3 gene

species of mammals and birds registered in GenBank, further confirmation in recently reported IFITM3 sequences is needed in the future (Bassano et al. 2017). In a previous topology study in the human IFITM3 protein, substantial evidence indicated that the human IFITM3 protein favors the cytosolic Nterminus. Our prediction suggested that birds have an inverted topology in their IFITM3 protein compared to that of the human IFITM3 protein, implying that the chicken IFITM3 protein prefers the extracellular N-terminus. Because the clathrin adaptor protein complex interacts with cytoplasmic tails of membrane proteins, the position of the signal motif is important to the endosomal pathway of a protein (Traub and Bonifacino 2013). In the human clathrin adaptor protein complex, AP-2 recognizes the YEML motif, and the NTD of the human IFITM3 protein prefers the cytosolic N-terminus (Bailey et al. 2013). However, IFITM3 protein in birds does not likely use the $\mathrm{Y} \times \mathrm{x} \phi$ motif and shows inverted topology to this protein in mammals. Since the evolutionally conserved sorting sequence of the IFITM3 protein malfunctions in birds, it will be valuable to study whether the well-conserved CTD of birds, which is predicted to exist in the same compartment with the clathrin adaptor protein complex, acts as an atypical sorting signal.

Genetic polymorphisms in disease-associated genes can influence the susceptibility to disease onset (Jeong et al. 2005a; Jeong et al. 2005b; Kim and Jeong 2017a). Previous 
Table 2 Genotype and allele frequencies of IFITM3 gene polymorphisms in chickens

\begin{tabular}{|c|c|c|c|c|c|c|c|c|c|}
\hline \multirow{2}{*}{$\frac{\text { Polymorphism }}{\text { c. }-338 \mathrm{G}>\mathrm{A}}$} & \multirow[t]{2}{*}{ Breeds } & \multicolumn{3}{|c|}{ Genotype frequency, n (\%) } & \multirow[t]{2}{*}{$P$ value } & \multicolumn{2}{|c|}{ Allele frequency, $\mathrm{n}(\%)$} & \multirow[t]{2}{*}{$P$ value } & \multirow[t]{2}{*}{ HWE } \\
\hline & & GG & GA & AA & & G & $\mathrm{A}$ & & \\
\hline & Dekalb White & $26(24.07)$ & $56(51.85)$ & $26(24.07)$ & $P<0.001$ & $108(50)$ & $108(50)$ & 1.0 & 0.7003 \\
\hline & Ross & $31(43.06)$ & $10(13.89)$ & $31(43.06)$ & & $72(50)$ & $72(50)$ & & $P<0.0001$ \\
\hline \multirow[t]{3}{*}{ c. $-330 \mathrm{G}>\mathrm{C}$} & & GG & GC & $\mathrm{CC}$ & & G & $\mathrm{C}$ & & \\
\hline & Dekalb White & $26(24.07)$ & $56(51.85)$ & $26(24.07)$ & $P<0.0001$ & $108(50)$ & $108(50)$ & $P<0.0001$ & 0.7003 \\
\hline & Ross & $12(16.67)$ & $6(8.33)$ & $54(75)$ & & $30(20.83)$ & $114(79.17)$ & & $P<0.0001$ \\
\hline \multirow[t]{3}{*}{ c. $-295 \mathrm{G}>\mathrm{T}$} & & GG & GT & $\mathrm{TT}$ & & G & $\mathrm{T}$ & & \\
\hline & Dekalb White & $108(100)$ & $0(0)$ & $0(0)$ & $P<0.0001$ & $216(100)$ & $0(0)$ & $P<0.0001$ & - \\
\hline & Ross & $56(77.78)$ & $12(16.67)$ & $4(5.56)$ & & $124(86.11)$ & $20(13.89)$ & & 0.0101 \\
\hline \multirow[t]{3}{*}{ c. $213+18 \mathrm{G}>\mathrm{T}$} & & GG & GT & $\mathrm{TT}$ & & G & $\mathrm{T}$ & & \\
\hline & Dekalb White & $28(25.93)$ & $54(50)$ & $26(24.07)$ & $P<0.0001$ & $110(50.93)$ & $106(49.07)$ & $P<0.0001$ & 0.9972 \\
\hline & Ross & 49 (68.06) & $8(11.11)$ & $15(20.83)$ & & $106(73.61)$ & $38(26.39)$ & & $P<0.0001$ \\
\hline \multirow[t]{3}{*}{ c. $214-5 \mathrm{C}>\mathrm{T}$} & & $\mathrm{CC}$ & $\mathrm{CT}$ & TT & & $\mathrm{C}$ & $\mathrm{T}$ & & \\
\hline & Dekalb White & $108(100)$ & $0(0)$ & $0(0)$ & $P<0.0001$ & $216(100)$ & $0(0)$ & $P<0.0001$ & - \\
\hline & Ross & $38(52.78)$ & $6(8.33)$ & $28(38.89)$ & & $82(56.94)$ & $62(43.06)$ & & $P<0.0001$ \\
\hline c. $298 \mathrm{C}>\mathrm{A}$ & & $\mathrm{CC}$ & $\mathrm{CA}$ & $\mathrm{AA}$ & & $\mathrm{C}$ & $\mathrm{A}$ & & \\
\hline \multirow[t]{2}{*}{$(\mathrm{L} 100 \mathrm{M})$} & Dekalb White & $102(94.44)$ & $6(5.56)$ & $0(0)$ & 0.2454 & $210(97.22)$ & $6(2.78)$ & 0.2502 & 0.7665 \\
\hline & Ross & $71(98.61)$ & $1(1.39)$ & $0(0)$ & & $143(99.31)$ & $1(0.69)$ & & 0.9527 \\
\hline c. $307 \mathrm{G}>\mathrm{A}$ & & GG & GA & $\mathrm{AA}$ & & G & $\mathrm{A}$ & & \\
\hline \multirow[t]{2}{*}{ (V103I) } & Dekalb White & $58(53.7)$ & $27(25)$ & $23(21.3)$ & $P<0.0001$ & $143(66.2)$ & $73(33.8)$ & $P<0.0001$ & $P<0.001$ \\
\hline & Ross & 19 (26.39) & $9(12.5)$ & $44(61.11)$ & & 47 (32.64) & 97 (67.36) & & $P<0.0001$ \\
\hline c. $373 \mathrm{~A}>\mathrm{C}$ & & AA & $\mathrm{AC}$ & $\mathrm{CC}$ & & $\mathrm{A}$ & $\mathrm{C}$ & & \\
\hline \multirow[t]{2}{*}{$(\mathrm{N} 125 \mathrm{H})$} & Dekalb White & $108(100)$ & $0(0)$ & $0(0)$ & 0.0624 & $216(100)$ & $0(0)$ & 0.0632 & - \\
\hline & Ross & $69(95.83)$ & $3(4.17)$ & $0(0)$ & & $141(97.92)$ & $3(2.08)$ & & 0.8567 \\
\hline \multirow[t]{3}{*}{ c. $444 \mathrm{G}>\mathrm{A}$} & & GG & GA & AA & & G & A & & \\
\hline & Dekalb White & $104(96.3)$ & $4(3.7)$ & $0(0)$ & 0.151 & $212(98.15)$ & $4(1.85)$ & 0.1531 & 0.8446 \\
\hline & Ross & $72(100)$ & $0(0)$ & $0(0)$ & & $144(100)$ & $0(0)$ & & - \\
\hline \multirow[t]{3}{*}{ c. $493 \mathrm{~A}>\mathrm{C}$} & & AA & $\mathrm{AC}$ & $\mathrm{CC}$ & & A & $\mathrm{C}$ & & \\
\hline & Dekalb White & $91(84.26)$ & $10(9.26)$ & $7(6.48)$ & 0.0664 & $192(88.89)$ & $24(11.11)$ & $P<0.01$ & $P<0.001$ \\
\hline & Ross & $67(93.06)$ & $5(6.94)$ & $0(0)$ & & $139(96.53)$ & $5(3.47)$ & & 0.7602 \\
\hline \multirow[t]{3}{*}{ c. $657+29 \mathrm{~T}>\mathrm{G}$} & & $\mathrm{TT}$ & TG & GG & & $\mathrm{T}$ & G & & \\
\hline & Dekalb White & $47(43.52)$ & $28(25.93)$ & $33(30.56)$ & $P<0.0001$ & $122(56.48)$ & $94(43.52)$ & $P<0.0001$ & $P<0.001$ \\
\hline & Ross & $14(19.44)$ & $4(5.56)$ & $54(75)$ & & $32(22.22)$ & $112(77.78)$ & & $P<0.0001$ \\
\hline \multirow{3}{*}{$\begin{array}{c}\text { c. } 657+47- \\
657+ \\
48 \text { InsAG }\end{array}$} & & $\mathrm{Wt} / \mathrm{Wt}$ & $\mathrm{Wt} / \mathrm{Ins}$ & Ins/Ins & & $\mathrm{Wt}$ & Ins & & \\
\hline & Dekalb White & $76(70.37)$ & $20(18.52)$ & $12(11.11)$ & $P<0.0001$ & $172(79.63)$ & $44(20.37)$ & $P<0.0001$ & $P<0.001$ \\
\hline & Ross & $71(98.61)$ & $0(0)$ & $1(1.39)$ & & $142(98.61)$ & $2(1.39)$ & & $P<0.0001$ \\
\hline \multirow[t]{3}{*}{ c. $657+47 \mathrm{C}>\mathrm{A}$} & & $\mathrm{CC}$ & $\mathrm{CA}$ & AA & & G & $\mathrm{C}$ & & \\
\hline & Dekalb White & $101(93.52)$ & $7(6.48)$ & $0(0)$ & 0.0966 & 209 (96.76) & $7(3.24)$ & 0.7456 & 0.7278 \\
\hline & Ross & $70(97.22)$ & $1(1.39)$ & $1(1.39)$ & & $141(97.92)$ & $3(2.08)$ & & $P<0.0001$ \\
\hline \multirow[t]{3}{*}{ c. $657+64 \mathrm{~T}>\mathrm{C}$} & & $\mathrm{TT}$ & $\mathrm{TC}$ & $\mathrm{CC}$ & & $\mathrm{T}$ & $\mathrm{C}$ & & \\
\hline & Dekalb White & $78(72.22)$ & $6(5.56)$ & $24(22.22)$ & $P<0.001$ & $162(75.00)$ & $54(25.00)$ & $P<0.0001$ & $P<0.001$ \\
\hline & Ross & $65(90.28)$ & $5(6.94)$ & $2(2.78)$ & & 135 (93.75) & $9(6.25)$ & & $P<0.001$ \\
\hline
\end{tabular}

studies have reported that SNPs in the IFITM3 gene are associated with several diseases, especially the 2009 IAV pandemic and UC. The rs12252 SNP, which is located in the ORF, showed a significant association with disease severity in the 2009 IAV pandemic. In addition, a previous genome-wide association study (GWAS) indicated that UC is associated with an SNP in the IFITM3 gene. A subsequent study reported that the distribution of rs3888188 SNP in the IFITM3 gene correlated with the number of UC patients (Seo et al. 2010; Wu et al. 2007). Furthermore, rs3888188 SNP is associated 


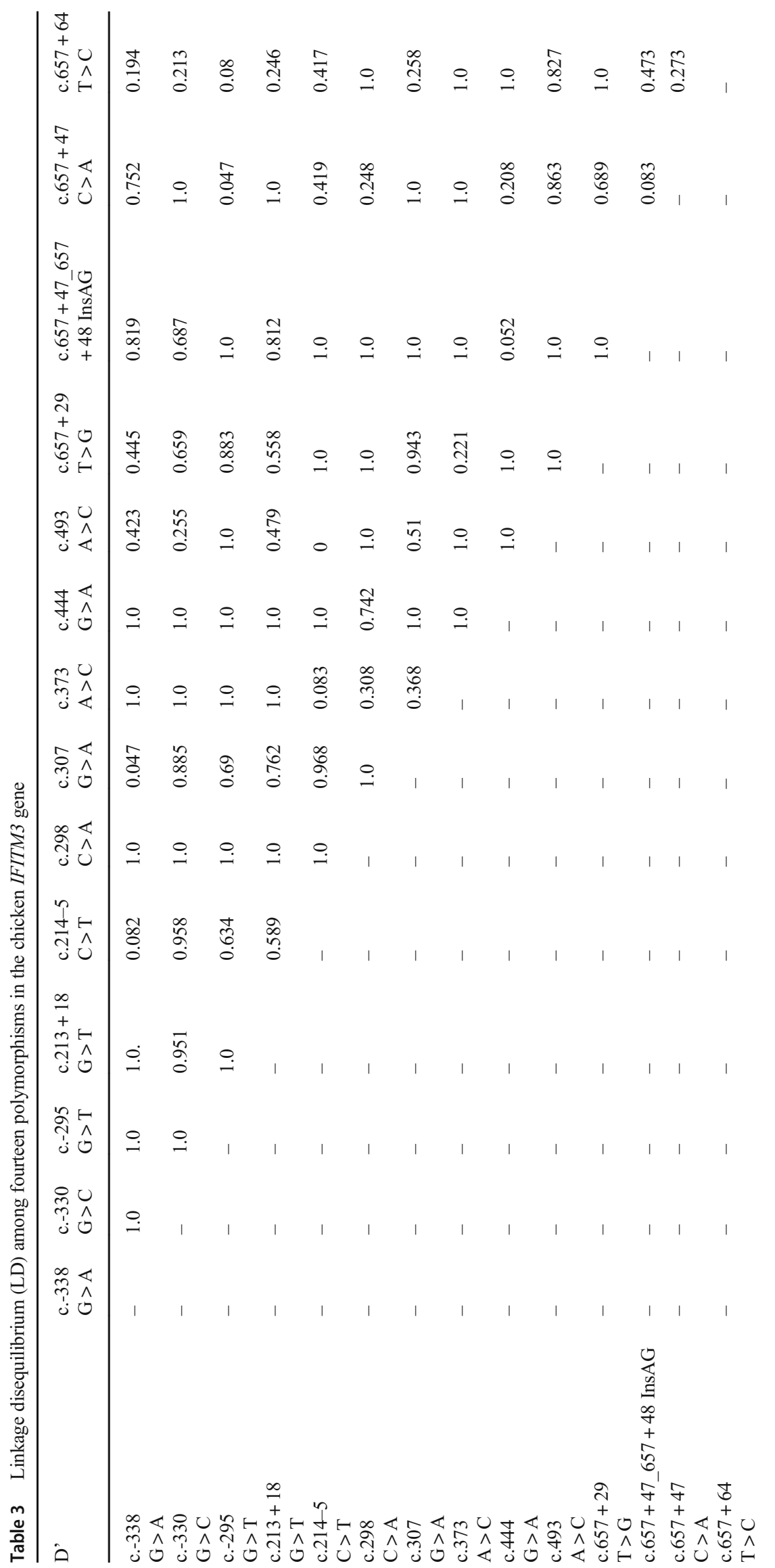




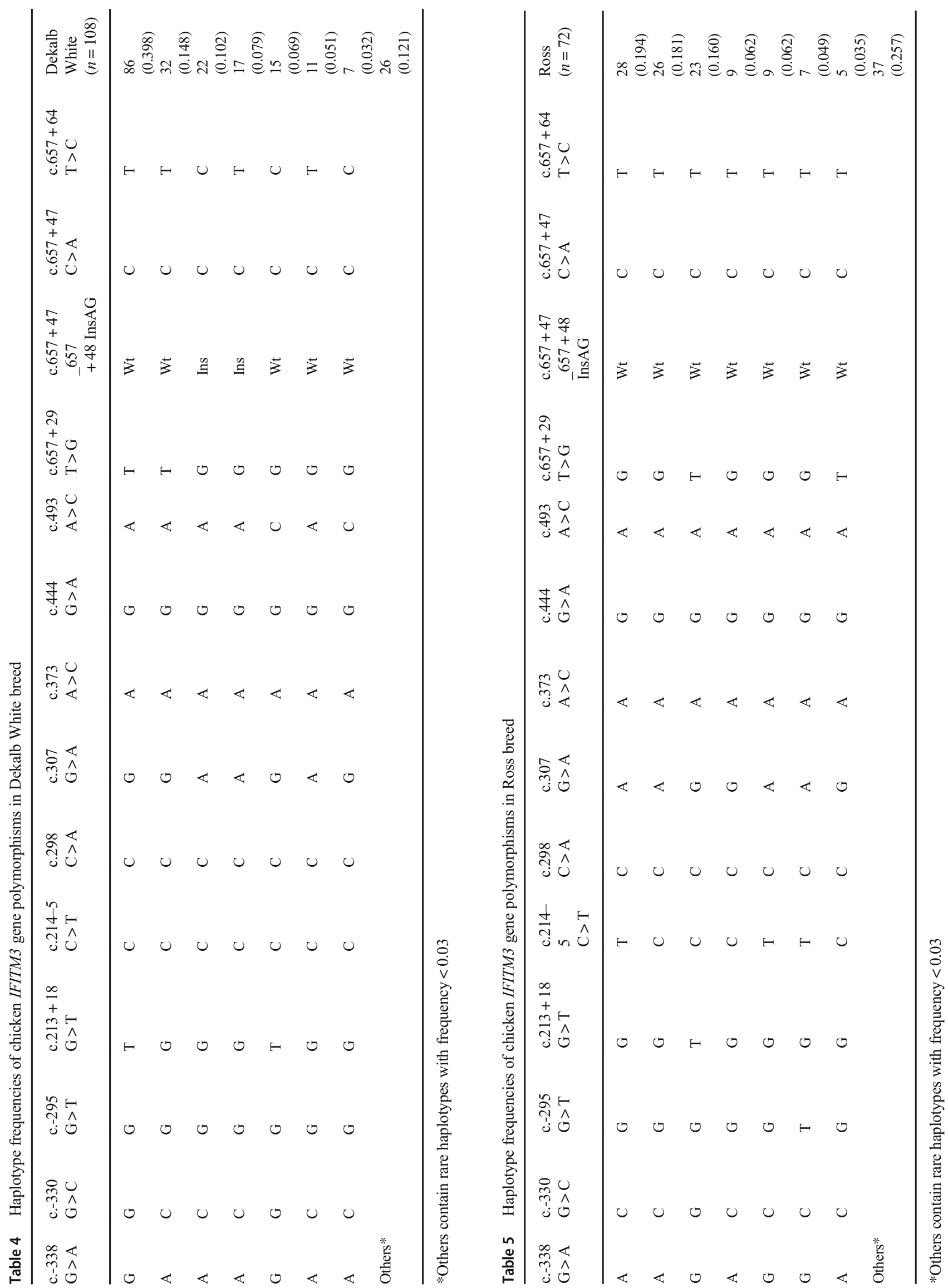


Table 6 Transmembrane domain changes in IFITM3 protein according to polymorphisms predicted by SOSUI

\begin{tabular}{llllll}
\hline Prediction method & Polymorphism & Transmembrane domain & Position & Length & TM* \\
\hline SOSUI & $100 \mathrm{~L} / 103 \mathrm{~V} / 125 \mathrm{~N}$ & HLINVFLIILIIALVASGTIMVA & $99-121$ & 23 & TM2 \\
& $100 \mathrm{~L} / 103 \mathrm{~V} / 125 \mathrm{H}$ & HLINVFLIILIIALVASGTIMVA & $99-121$ & 23 & TM2 \\
& $100 \mathrm{~L} / 103 \mathrm{I} / 125 \mathrm{~N}$ & HLINIFLIILIIALVASGTIMVA & $99-121$ & 23 & TM2 \\
& $100 \mathrm{~L} / 103 \mathrm{I} / 125 \mathrm{H}$ & HLINIFLIILIIALVASGTIMVA & $99-121$ & 23 & $\mathrm{TM} 2$ \\
& $100 \mathrm{M} / 103 \mathrm{~V} / 125 \mathrm{~N}$ & INVFLIILIIALVASGTIMVANI & $101-123$ & 23 & $\mathrm{TM} 2$ \\
& $100 \mathrm{M} / 103 \mathrm{~V} / 125 \mathrm{H}$ & INIFLIILIIALVASGTIMVANI & $101-123$ & 23 & TM2 \\
& $100 \mathrm{M} / 103 \mathrm{I} / 125 \mathrm{~N}$ & INIFLIILIIALVASGTIMVANI & $101-123$ & 23 & TM2 \\
& $100 \mathrm{M} / 103 \mathrm{I} / 125 \mathrm{H}$ & INIFLIILIIALVASGTIMVANI & $101-123$ & 23 & TM2 \\
\hline
\end{tabular}

*TM indicates transmembrane domain with the infection rate of tuberculosis and recent studies reported that the IFITM3 protein exhibited a broad spectrum of immune responses to variable pathogens, including not only enveloped viruses but also non-enveloped viruses and bacteria (Anafu et al. 2013; Naderi et al. 2016; Ranjbar et al. 2015). Because the IFITM3 protein participates in the host immune response and polymorphisms in the IFITM3 gene dramatically affect immune capacity, we performed direct sequencing and found ten SNPs and one in/del in the chicken IFITM3 gene (Table 2, Fig. 3), suggesting that the chicken IFITM3 gene is highly polymorphic. Because the IFITM3 gene is an important immune-related gene, its highly polymorphic property may affect to antiviral ability. Remarkably, L100 M and N125H were predicted to be 'probably damaging' by PolyPhen-2 (data not shown). Since the non-synonymous SNPs are located in TM2 and can influence the topology of the transmembrane domain, we performed transmembrane prediction (Table 6).
Interestingly, the $\mathrm{L} 100 \mathrm{M}$ polymorphism changed the position of the TM2 domain and the length of the CIL domain. Since the CIL domain belongs to CD225, which is a well-conserved structure of the IFITM3 protein among species and is significantly associated with antiviral capacity, it will be important to determine these influences on host immune capacity.

The expression of IFITM3 gene in the duck is strongly elevated in response to highly pathogenic avian influenza infection, whereas that in the chicken is shown different pattern. This result suggests that ducks are more resistant to avian influenza infection than chickens (Smith et al. 2015). In several studies, broiler breed seemed to be generally more resistant to avian influenza infection than layer breed in chickens. Thus, we investigated genetic difference of the IFITM3 gene between Dekalb white as layer breed and Ross as broiler breed. Interestingly, the genotype and allele frequencies of V103I polymorphism of the IFITM3 gene showed

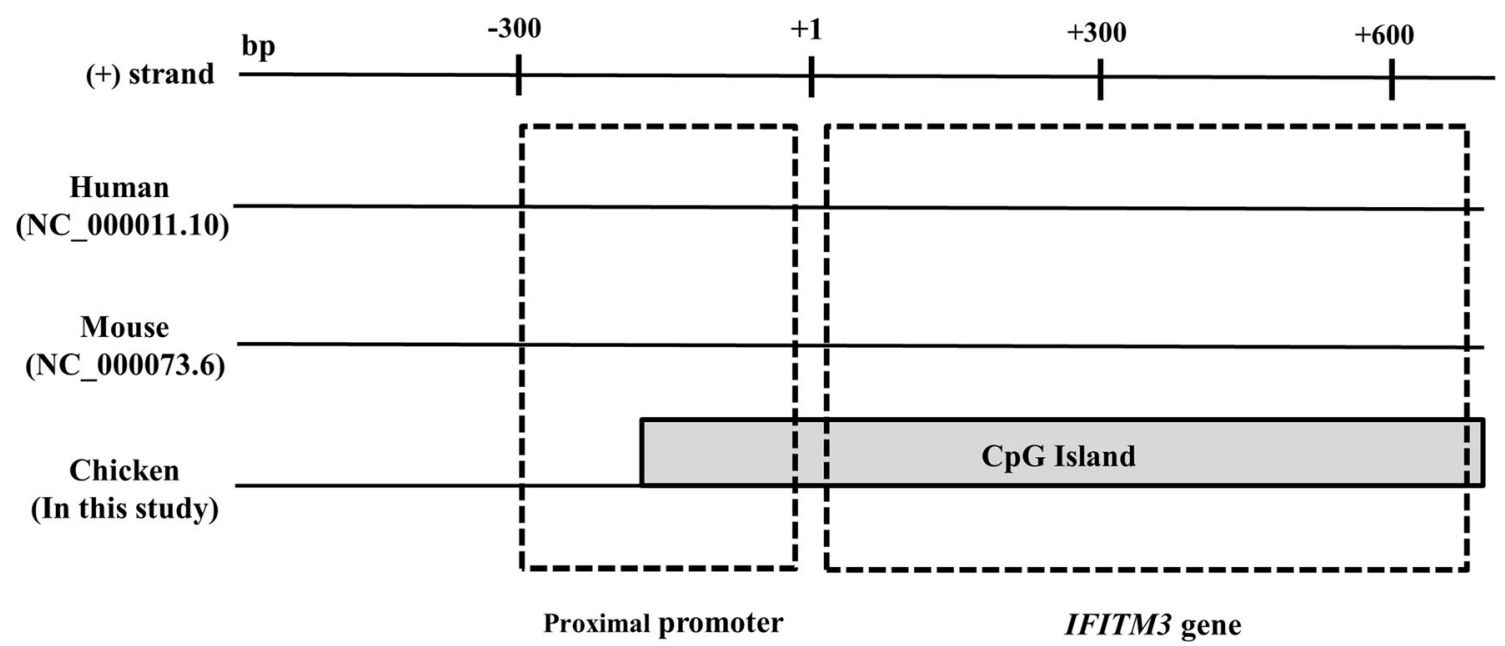

Fig. 4 Comparison of the IFITM3 gene promoter architecture in humans, mice and chickens. IFITM3 nucleotide sequences were obtained from GenBank at NCBI, including those of humans (Homo sapiens, NC 000011.10), mice (Mus musculus, NC 000073.6), and chickens (Gallus gallus, in this study). The TATA box was predicted by the Naive Bayes model and $\mathrm{CpG}$ islands (CGIs) were predicted by GPMiner. The left dotted box indicates the proximal promoter region, which is located $300 \mathrm{bp}$ upstream of the transcription start site. The right dotted box indicates the body of the IFITM3 gene 
significantly different distributions between 2 chicken breeds $(P<0.0001)$ (Table 2). To identify the difference of antiviral function according to alleles of V103I polymorphism of IFITM3 gene, which showed significant difference between Dekalb White and Ross, further study is highly desirable in the future.

The immune system differs substantially between mammals and birds (Kaiser 2010). Because the structure and predicted topology of the IFITM3 protein differ between these two groups, we hypothesized that the structure of the IFITM3 gene also differs. We investigated important promoter elements, including the TATA box and CGIs, in humans, mice and chickens (Fig. 4). In mammals, the IFITM3 gene does not contain a TATA box or CGI within the proximal promoter. Interestingly, the promoter structure of the chicken IFITM3 gene differs significantly compared to mammals, chickens contain a CGI only. Although the promoter can be classified above ten types according to its structure, briefly, based on the presence of two major components, the TATA box and CGIs, the promoter can be classified into 4 types. Among them, a TATA-/CGI- classified promoter is regulated in a tissuespecific manner and a TATA-/CGI+ classified promoter is regulated in a house-keeping manner (Danino et al. 2015; Juven-Gershon and Kadonaga 2010; Lenhard et al. 2012; $\mathrm{Zhu}$ et al. 2008). According to these classifications, the IFITM3 gene in mammals is predicted to be regulated in a tissue-specific manner and the chicken IFITM3 gene is predicted to be regulated in a house-keeping manner. It is important to note that the proximal promoter region of the IFITM3 gene differs significantly among several species. We look forward to confirming how this difference affects the immune system in a future study. Further study based on our baseline data is highly desirable to verify the differences of promoter structure of IFITM3 gene, because IFITM3 protein evolutionally well-conserved in several species and has crucial role in host immune systems (Chen et al. 2017; Smith et al. 2013; Zhang et al. 2012). Because our analysis has been performed on only limited $300 \mathrm{bp}$ upstream region of the IFITM3 gene, further investigation of enlarged upstream region $(\sim 500 \mathrm{bp})$ of this gene and distal promoter is highly desirable to validate the feature of chicken IFITM3 gene identified in the present study.

\section{Conclusion}

Collectively, we investigated the structure of the IFITM3 protein and genetic characteristics of the IFITM3 gene. We noted structural difference in the IFITM3 protein between mammals and birds and visualized topological differences. We also first reported genetic distribution of polymorphisms in the chicken IFITM3 gene and performed novel methods to evaluate nonsynonymous SNP using transmembrane topology prediction.
Lastly, we identified differences in the promoter architecture between mammals and chickens.

Acknowledgements This research was supported by the Basic Science Program through the National Research Foundation of Korea (NRF), funded by the Ministry of Education, Science and Technology (2015R1D1A1A01059945; 2018R1D1A1B07048711). This research was also supported by Basic Science Research Program through the National Research Foundation of Korea (NRF) funded by the Ministry of Education (2017R1A6A1A03015876). Mr. Yong-Chan Kim and Ms. Min-Ju Jeong were supported by the BK21 Plus program in the Department of Bioactive Material Sciences.

\section{Compliance with ethical standards}

Conflict of interest The authors declared no conflict of interest.

\section{References}

Anafu AA, Bowen CH, Chin CR, Brass AL, Holm GH (2013) Interferoninducible Transmembrane Protein 3 (IFITM3) Restricts Reovirus Cell Entry. J Biol Chem 288(24):17261-17271

Bailey CC, Kondur HR, Huang IC, Farzan M (2013) Interferon-induced transmembrane protein 3 is a type II transmembrane protein. J Biol Chem 288(45):32184-32193

Bassano I, Ong SH, Lawless N, Whitehead T, Fife M, Kellam P (2017) Accurate characterization of the IFITM locus using MiSeq and PacBio sequencing shows genetic variation in Galliformes. BMC Genomics 30(18):419

Blyth GA, Chan WF, Webster RG, Magor KE (2015) Duck interferoninducible transmembrane protein 3 mediates restriction of influenza viruses. J Virol 90(1):103-116

Brass AL, Huang IC, Benita Y, John SP, Krishnan MN, Feeley EM, Ryan BJ, Weyer JL, van der Weyden L, Fikrig E, Adams DJ, Xavier RJ, Farzan M, Elledge SJ (2009) The IFITM proteins mediate cellular resistance to influenza a H1N1 virus, West Nile virus, and dengue virus. Cell 139(7):1243-1254

Chen S, Wang L, Chen J, Zhang L, Wang S, Goraya MU, Chi X, Na Y, Shao W, Yang Z, Zeng X, Chen S, Chen JL (2017) Avian interferoninducible transmembrane protein family effectively restricts avian Tembusu virus infection. Front Microbiol 8:672

Danino YM, Even D, Ideses D, Juven-Gershon T (2015) The core promoter: at the heart of gene expression. Biochim Biophys Acta 1849(8):1116-1131

Diamond MS, Farzan M (2013) The broad-spectrum antiviral functions of IFIT and IFITM proteins. Nat Rev Immunol 13(1):46-57

Everitt AR, Clare S, Pertel T, John SP, Wash RS, Smith SE, Chin CR, Feeley EM, Sims JS, Adams DJ, Wise HM, Kane L, Goulding D, Digard P, Anttila V, Baillie JK, Walsh TS, Hume DA, Palotie A, Xue Y, Colonna V, Tyler-Smith C, Dunning J, Gordon SB, Gen II, Investigators M, Smyth RL, Openshaw PJ, Dougan G, Brass AL, Kellam P (2012) IFITM3 restricts the morbidity and mortality associated with influenza. Nature 484(7395):519-523

Feeley EM, Sims JS, John SP, Chin CR, Pertel T, Chen LM, Gaiha GD, Ryan BJ, Donis RO, Elledge SJ, Brass AL (2011) IFITM3 inhibits influenza a virus infection by preventing cytosolic entry. PLoS Pathog 7(10):e1002337

Friedman RL, Manly SP, McMahon M, Kerr IM, Stark GR (1984) Transcriptional and posttranscriptional regulation of interferoninduced gene expression in human cells. Cell 38(3):745-755

Jeong BH, Kim NH, Choi EK, Lee C, Song YH, Kim JI, Carp RI, Kim YS (2005a) Polymorphism at 3' UTR +28 of the prion-like protein 
gene is associated with sporadic Creutzfeldt-Jakob disease. Eur J Hum Genet 13(9):1094-1097

Jeong BH, Lee KH, Kim NH, Jin JK, Kim JI, Carp RI, Kim YS (2005b) Association of sporadic Creutzfeldt-Jakob disease with homozygous genotypes at PRNP codons 129 and 219 in the Korean population. Neurogenetics 6(4):229-232

Jia R, Pan Q, Ding S, Rong L, Liu SL, Geng Y, Qiao W, Liang C (2012) The N-terminal region of IFITM3 modulates its antiviral activity by regulating IFITM3 cellular localization. J Virol 86(24):1369713707

Jia R, Xu F, Qian J, Yao Y, Miao C, Zheng YM, Liu SL, Guo F, Geng Y, Qiao W, Liang C (2014) Identification of an endocytic signal essential for the antiviral action of IFITM3. Cell Microbiol 16(7):1080 1093

John SP, Chin CR, Perreira JM, Feeley EM, Aker AM, Savidis G, Smith SE, Elia AE, Everitt AR, Vora M, Pertel T, Elledge SJ, Kellam P, Brass AL (2013) The CD225 domain of IFITM3 is required for both IFITM protein association and inhibition of influenza a virus and dengue virus replication. J Virol 87(14):7837-7852

Juven-Gershon T, Kadonaga JT (2010) Regulation of gene expression via the core promoter and the basal transcriptional machinery. Dev Biol 339(2):225-229

Kaiser P (2010) Advances in avian immunology-prospects for disease control: a review. Avian Pathol 39(5):309-324

Kim YC, Jeong BH (2017a) Lack of germline mutation at codon 211 of the prion protein gene (PRNP) in Korean native cattle. Acta Vet Hung 65(1):147-152

Kim YC, Jeong BH (2017b) No correlation of the disease severity of influenza a virus infection with the rs 12252 polymorphism of the interferon-induced transmembrane protein 3 gene. Intervirology 60(1-2):69-74

Lenhard B, Sandelin A, Carninci P (2012) Metazoan promoters: emerging characteristics and insights into transcriptional regulation. Nat Rev Genet 13(4):233-245

Li K, Markosyan RM, Zheng YM, Golfetto O, Bungart B, Li M, Ding S, He Y, Liang C, Lee JC, Gratton E, Cohen FS, Liu SL (2013) IFITM proteins restrict viral membrane hemifusion. PLoS Pathog 9(1): e1003124

Naderi M, Hashemi M, Abedipour F, Bahari G, Rezaei M, Taheri M (2016) Evaluation of interferon-induced transmembrane protein-3 (IFITM3) rs7478728 and rs3888188 polymorphisms and the risk of pulmonary tuberculosis. Biomed Rep 5(5):634-638

Ranjbar S, Haridas V, Jasenosky LD, Falvo JV, Goldfeld AE (2015) A role for IFITM proteins in restriction of mycobacterium tuberculosis infection. Cell Rep 13(5):874-883

Santhakumar D, Rubbenstroth D, Martinez-Sobrido L, Munir M (2017) Avian interferons and their antiviral effectors. Front Immunol 31(8): 49

Savidis G, Perreira JM, Portmann JM, Meraner P, Guo Z, Green S, Brass AL (2016) The IFITMs inhibit Zika virus replication. Cell Rep 15(11):2323-2330

Schoggins JW, Wilson SJ, Panis M, Murphy MY, Jones CT, Bieniasz P, Rice CM (2011) A diverse range of gene products are effectors of the type I interferon antiviral response. Nature 472(7344):481-485
Seo GS, Lee JK, Yu JI, Yun KJ, Chae SC, Choi SC (2010) Identification of the polymorphisms in IFITM3 gene and their association in a Korean population with ulcerative colitis. Exp Mol Med 42(2):99104

Smith SE, Gibson MS, Wash RS, Ferrara F, Wright E, Temperton N, Kellam P, Fife M (2013) Chicken interferon-inducible transmembrane protein 3 restricts influenza viruses and lyssaviruses in vitro. J Virol 87(23):12957-12966

Smith J, Smith N, Yu L, Paton IR, Gutowska MW, Forrest HL, Danner AF, Seiler JP, Digard P, Webster RG, Burt DW (2015) A comparative analysis of host responses to avian influenza infection in ducks and chickens highlights a role for the interferon-induced transmembrane proteins in viral resistance. BMC Genomics 4(16):574

Traub LM, Bonifacino JS (2013) Cargo recognition in clathrin-mediated endocytosis. Cold Spring Harb Perspect Biol 5(11):a016790

Wang A, Sun L, Wang M, Jia R, Zhu D, Liu M, Sun K, Yang Q, Wu Y, Chen X, Cheng A, Chen S (2017) Identification of IFITM1 and IFITM3 in goose: gene structure, expression patterns, and immune Reponses against Tembusu virus infection. Biomed Res Int 2017: 5149062

Weidner JM, Jiang D, Pan XB, Chang J, Block TM, Guo JT (2010) Interferon-induced cell membrane proteins, IFITM3 and tetherin, inhibit vesicular stomatitis virus infection via distinct mechanisms. J Virol 84(24):12646-12657

Wu F, Dassopoulos T, Cope L, Maitra A, Brant SR, Harris ML, Bayless TM, Parmigiani G, Chakravarti S (2007) Genome-wide gene expression differences in Crohn's disease and ulcerative colitis from endoscopic pinch biopsies: insights into distinctive pathogenesis. Inflamm Bowel Dis 13(7):807-821

Xuan Y, Wang LN, Li W, Zi HR, Guo Y, Yan WJ, Chen XB, Wei PM (2015) IFITM3 rs12252 T>C polymorphism is associated with the risk of severe influenza: a meta-analysis. Epidemiol Infect 143(14): 2975-2984

Xu-Yang Z, Pei-Yu B, Chuan-Tao Y, Wei Y, Hong-Wei M, Kang T, ChunMei Z, Ying-Feng L, Xin W, Ping-Zhong W, Chang-Xing H, XueFan B, Ying Z, Zhan-Sheng J (2016) Interferon-induced transmembrane protein 3 inhibits Hantaan virus infection, and its single nucleotide polymorphism rs 12252 influences the severity of hemorrhagic fever with renal syndrome. Front Immunol 7:535

Zhang Z, Liu J, Li M, Yang H, Zhang C (2012) Evolutionary dynamics of the interferon-induced transmembrane gene family in vertebrates. PLoS One 7(11):e49265

Zhang YH, Zhao Y, Li N, Peng YC, Giannoulatou E, Jin RH, Yan HP, Wu H, Liu JH, Liu N, Wang DY, Shu YL, Ho LP, Kellam P, McMichael A, Dong T (2013) Interferon-induced transmembrane protein-3 genetic variant rs $12252-\mathrm{C}$ is associated with severe influenza in Chinese individuals. Nat Commun 4:1418

Zhu J, He F, Hu S, Yu J (2008) On the nature of human housekeeping genes. Trends Genet 24(10):481-484

Publisher's note Springer Nature remains neutral with regard to jurisdictional claims in published maps and institutional affiliations. 